\title{
Synthesis, Antimicrobial, Antioxidant and Docking Study of Novel Isoxazoline Derivatives
}

Ghosoun Laftaa Mohsen ${ }^{1}$, Ahmed Mutanabbi Abdula ${ }^{1 *}$,

Abdulkadir Mohammed Noori Jassim ${ }^{1}$

1 Mustansiriyah University, Department of Chemistry, Baghdad, Iraq.

\section{ABSTRACT}

A novel series of isoxazoline derivatives (3-10) was synthesized and characterized by using spectral analysis. The synthesized derivatives were in vitro screened against several bacterial species as well as Candida albicans and exhibit moderate to potent activity. All the synthesized products were screened qualitatively for their antioxidant property by using TLC technique and the percent DPPH radical scavenging activity of the potent derivatives $(4-6,8)$ were evaluated. Docking study of isoxazoline derivatives 7 and 8 against L-Glutamine: D-fructose-6-phosphate amidotransferase (glucosamine-6-phosphate synthase), the target enzyme in antimicrobial chemotherapy, was evaluated to explore the interactions of the synthesized hits inside the amino acid residues of the enzyme active site. The docking outcomes strongly supported the in vitro assay of new derivatives against several microbial species.

Keywords: Isoxazoline, antimicrobial, antioxidant, docking study.

\section{INTRODUCTION}

Synthesis and evaluation of efficacious antimicrobial, due to limited number of effective drugs ${ }^{1}$ and antioxidant agents to protect human body from free radicals ${ }^{2}$ represent the main goal for the several research groups worldwide. Recently, considerable attention has been given to isoxazoline derivatives due to their varied pharmacological activities like antimicrobial ${ }^{3}$, anti-inflammatory ${ }^{4}$, anti-tubercular $^{5}$, antidepressant ${ }^{6}$, antioxidant ${ }^{7}$, antitumor and DNA Methyltransferase 1 Inhibitors $^{8}$. Therefore, our attempts to find novel antimicrobial and antioxidant agents focus on the isoxazoline derivative. A novel series of isoxazolines (3-10) were synthesized and characterized by spectral data. Isoxazoline derivatives (3- 
10) were In vitro screened against several bacterial species (gram positive and garm negative) as well as Candida albicans and found to exhibit moderate to potent activity. The synthesized derivatives screened for their reducing properties with 2, 2-diphenyl-l-picrylhydrazyl (DPPH) radical by the TLC autographic. The percent of DPPH scavenging by using spectrophotometric assay for isoxazoline derivatives $(4-6,8)$ which exhibited strong yellow or blue fluorescence under UV light in TLC autographic was evaluated. Docking study of the potent antimicrobial derivatives $(7,8)$ against L-Glutamine: D-fructose-6-phosphate amidotransferase $^{9}$, the specific target for antibacterial and antifungal agents, was achieved to explore and explain the interactions of the discovered hits within the amino acid residues of the enzyme active pocket. The docking results enhanced the activity of new derivatives as promising antimicrobial agents. Autodock 4.2, the efficacious tool for examining the binding alliance of small ligand to enzyme binding pocket ${ }^{10}$ was applied to explore the interactions between the isoxazoline derivatives and the glucosamine-6-phosphate synthase active site.

\section{METHODOLOGY}

\section{General Synthesis}

All starting materials and solvents were obtained from Sigma-Aldrich and used without any additional purification. Melting points were measured on a electrothermal capillary apparatus and are uncorrected; FT-IR spectrum were recorded on a Shimadzu model FTIR-840oS. Mass spectra were obtained on a Shimadzu GCMS-QP2010 Ultra apparatus. 1H NMR spectra were achieved with a Bruker spectrophotometer model ultra-shield at $300 \mathrm{MHz}$ in $\mathrm{CDCl}_{3}$ or DMSO-d6 solution with the TMS as internal standard.

\section{Synthesis of (E)-1-(4-aminophenyl)-3-(3,4-dimethoxyphenyl)prop- 2-en-1-one (1)}

This compound was synthesized according to the procedure described in the published work ${ }^{11}$. Sodium hydroxide $(1 \mathrm{ml}, 40 \%)$ was added to a solution of $\mathrm{p}$ aminoacetophenone $(1 \mathrm{mmol})$ in ethanol $(10 \mathrm{~mL})$, and the reaction mixture was stirred for half hour. After that 3,4-dimethoxybenzaldehyde (1 mmol) was added and the reaction crude was stirred for $24 \mathrm{~h}$. The reaction crude was stand at the room temperature. The collected product was dried and purified from ethanol as recrystallizing solvent.

Yellow powder, yield 90\%, m.p 124-126 ${ }^{\circ} \mathrm{C}$; IR $\left(\mathrm{cm}^{-1}\right): 3445,3347\left(\mathrm{NH}_{2}\right), 3150$ (aromatic $C-H), 2963$ (aliphatic $C-H), 1642(C=O), 1598(C H=C H), 1579(C=C) .{ }^{1} \mathrm{H}$ NMR (3OOMHz, DMSO-d 6 ) $\delta$ (ppm): 3.81 (s, $3 \mathrm{H}, \mathrm{OCH}_{3}$ ), 3.86 (s,3H, OCH ) $_{3} 6.11$ (s, 2H, $\mathrm{NH}_{2}$ ), 6.61-7.95 (m, 9H, $\mathrm{Ar}-\mathrm{H}, \mathrm{CH}=\mathrm{CH}$ ). Mass (NCI) m/e: $283 \mathrm{M}^{+}$For
C17H17NO3. $R f=0.72$ (5:5, Hexane: Ethyl acetate).

\section{Synthesis of 4-(5-(3,4-dimethoxyphenyl)-4,5-dihydroisoxazol-3-yl) aniline (2)}

This compound was prepared as described in reference ${ }^{12}$. To the starting material $1(1 \mathrm{mmol})$ in ethanol (10ml), a mixture of sodium hydroxide $(40 \%, \mathrm{ml})$ and $\mathrm{NH} 2 \mathrm{OH} . \mathrm{HCl}(1.5 \mathrm{mmol})$ was added and the crude reaction was refluxed for $15 \mathrm{~h}$. The completion of reaction was monitored by a thin layer chromatography using ethyl actate: hexane system (1:1). The starting material was precipitate by adding crush ice then it was filtered, washing with water, dried and purified using ethanol as recrystallized solvent.

Orange powder, yield 90\%, m.p 110-113 ${ }^{\circ} \mathrm{C}$; IR (cm-1): $3365\left(\mathrm{NH}_{2}\right), 3001$ (aromatic $C-H), 2950$ (aliphatic $C-H), 1604(C=N), 1510(C=C) .{ }^{1} \mathrm{HNMR}$ (300 MHz, $\mathrm{CDCl}_{3}$ ) $\delta$ (ppm): 3.24-3.33 (dd, $1 \mathrm{H}, \mathrm{j}=8.7,16.5 \mathrm{~Hz}, \mathrm{CH}$ - isoxazoline), 3.64-3.70 (dd, $1 \mathrm{H}$, $\mathrm{j}=10.7,16.5 \mathrm{~Hz}, \mathrm{CH}$-isoxazoline),3.88 (s, $\left.2 \mathrm{H}, \mathrm{NH}_{2}\right), 3.94\left(\mathrm{~s}, 3 \mathrm{H}, \mathrm{OCH}_{3}\right), 3.96$ (s, $\left.3 \mathrm{H}, \mathrm{OCH}_{3}\right), 5.64(\mathrm{~m}, 1 \mathrm{H}, \mathrm{CH}$ - isoxazoline $), 6.70(\mathrm{~d}, \mathrm{j}=8.5 \mathrm{~Hz}, 2 \mathrm{H}, \mathrm{Ar}-\mathrm{H}), 6.85^{-}$ $6.96(\mathrm{~m}, 3 \mathrm{H}, A r-H), 7.52$ (d, j= 8.56, 2H, Ar-H). Mass (NCI) m/e: $298 \mathrm{M}^{+}$For

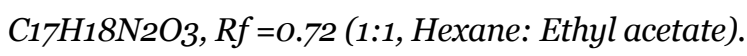

\section{Synthesis of Schiff bases (3-7)}

These compounds were prepared according to the procedure described in the published reference ${ }^{13}$. To solution of substituted benzaldehyde (1mmol) in methanol (10ml) with few drops of glacial acetic acid, isoxazoline compound 2 (1mmol) was added. The reaction crude was refluxed for 10-12 $\mathrm{h}$ and the reaction was checked by a thin layer chromatography (ethyl acetate:hexane ,1:1 and 3:7). The precipitate was filtered and washed with methanol, dried and recrystallized from ethanol.

\section{1-(4-(dimethoxymethyl)phenyl)-N-(4-(5-(3,4-dimethoxyphenyl)- 4,5-dihydroisoxazol-3-yl)phenyl)methanimine (3)}

Yellow off-white powder, yield 50\%, m.p 132-134 ${ }^{\circ} \mathrm{C}$; IR (cm-1): 3059 (aromatic $C-H$ ), 3001 (aliphatic $C-H), 1626(C H=N), 1610(C=N), 1521(C=C) .1 \mathrm{H}-\mathrm{NMR}$ (300MHz, $\mathrm{CDCl}_{3}$ ) $\delta$ (ppm): 3.32-3.41 (dd, j = 8.9, $16.5 \mathrm{~Hz}, 1 \mathrm{H}, \mathrm{CH}-\mathrm{isoxazoline}$ ), 3.72-3.81 (dd, j = 10.7, 16.4 Hz,1H, CH-isoxazoline), 3.89 (s, 3H, OCH3), 3.90 (s, $3 \mathrm{H}, \mathrm{OCH}_{3}$ ), 5.71 (m, $1 \mathrm{H}, \mathrm{CH}$-isoxazoline), 6.85-7.93 (m, 11H, Ar-H), $8.48(\mathrm{~s}, 1 \mathrm{H}$, $\mathrm{CH}=\mathrm{N}) . \mathrm{Rf}=0.78(1: 1$, Hexane: Ethylacetate $)$

N-(4-(5-(3,4-dimethoxyphenyl)-4,5-dihydroisoxazol-3-yl)phenyl)1-(1H-pyrrol-2-yl)methanimine (4)

Yellow powder, yield 75\%, m.p 173-175 ${ }^{\circ} \mathrm{C}$; IR $\left(\mathrm{cm}^{-1}\right)$ : $(\mathrm{N}-\mathrm{H}), 3055$ (aromatic $\mathrm{C}-\mathrm{H}$ ), (aliphatic $C-H), 1670(C H=N), 1593(C=\mathrm{N}), 1512(C=C) .{ }^{1} \mathrm{H}-\mathrm{NMR}(300 \mathrm{MHz}$, 
$\left.\mathrm{CDCl}_{3}\right) \delta(\mathrm{ppm}): 3.38-3.48\left(\mathrm{~m}, 1 \mathrm{H}, \mathrm{CH}\right.$ - isoxazoline), $3.73\left(\mathrm{~s}, 3 \mathrm{H}, \mathrm{OCH}_{3}\right), 3.81$ $3.86\left(\mathrm{~m}, 1 \mathrm{H}, \mathrm{CH}\right.$ - isoxazoline), $3.85\left(\mathrm{~s}, 3 \mathrm{H}, \mathrm{OCH}_{3}\right), 5.56(\mathrm{~m}, 1 \mathrm{H}, \mathrm{CH}$ - isoxazoline), 6.13-7.99 (m, 10H, $A r-H), 6.28(\mathrm{~s}, 1 \mathrm{H}, C H=N), 9.46(\mathrm{~s}, 1 \mathrm{H}, N-H)$. Mass (NCI) m/e: $375 \mathrm{M}^{+}$for $\mathrm{C}_{22} \mathrm{H}_{21} \mathrm{~N}_{3} \mathrm{O}_{3} . \mathrm{R}_{\mathrm{f}}=0.48$ (1:1, Hexane:Ethylacetate).

\section{N-(4-(5-(3,4-dimethoxyphenyl)-4,5-dihydroisoxazol-3-yl)phenyl)-}

\section{1-(4-nitrophenyl)methanimine (5)}

Yellow powder, yield 79\%, m.p 149-151 ${ }^{\circ} \mathrm{C}$; IR $\left(\mathrm{cm}^{-1}\right)$ : 3090 (aromatic $C-H$ ), 2997 (aliphatic $C-H), 1627(C H=N), 1599(C=N), 1521-1346$ Two band $(N-O) .{ }^{1} \mathrm{H}-$ NMR (30oMHz, $\left.\mathrm{CDCl}_{3}\right) \delta(\mathrm{ppm}): 3.40-3.49(\mathrm{~m}, 1 \mathrm{H}, \mathrm{CH}$-isoxazoline), $3.76(\mathrm{~s}, 3 \mathrm{H}$, $\mathrm{OCH}_{3}$ ), 3.79-3.88 (m, $1 \mathrm{H}, \mathrm{CH}$-isoxazoline), $3.84\left(\mathrm{~s}, 3 \mathrm{H}, \mathrm{OCH}_{3}\right), 5.67(\mathrm{~m}, 1 \mathrm{H}, \mathrm{CH}$ isoxazoline), $6.68(\mathrm{~s}, 1 \mathrm{H}, C H=N), 6.96-8.91(\mathrm{~m}, 11 \mathrm{H}, A r-H)$,. Mass $(\mathrm{NCI}) \mathrm{m} / \mathrm{e}: 429$ $\mathrm{M}^{+}$for $\mathrm{C}_{24} \mathrm{H}_{21} \mathrm{~N}_{3} \mathrm{O}_{5}, \mathrm{R}_{\mathrm{f}}=0.79$ (1:1, Hexane: Ethyl acetate).

\section{4-((4-(5-(3,4-dimethoxyphenyl)-4,5-dihydroisoxazol-3-yl)phenyl)} imino)methyl)-N,N-dimethylaniline (6)

Orange powder, yield 50\%, m.p 159-161 ${ }^{\circ} \mathrm{C}$; IR $\left(\mathrm{cm}^{-1}\right): 3080$ (aromatic $C-H$ ), 2968 (aliphatic $C-H), 1618(C H=N), 1606(C=N), 1521(C=C) .{ }^{1} \mathrm{H}-\mathrm{NMR}(300 \mathrm{MHz}$, $\left.\mathrm{CDCl}_{3}\right) \delta(\mathrm{ppm}): 3.07$ (s,6H, $\mathrm{N}\left(\mathrm{CH}_{3}\right) 2,3.29-3.37$ (dd, $1 \mathrm{H}, \mathrm{CH}$-isoxazoline, $\mathrm{j}=16.7$, $8.8 \mathrm{~Hz}$ ), 3.70-3.81 (dd, $1 \mathrm{H}, \mathrm{CH}$-isoxazoline, j = 16.5, $10.6 \mathrm{~Hz}$ ), 3.89 (s, $3 \mathrm{H}, \mathrm{OCH}_{3}$ ), $3.95\left(\mathrm{~s}, 3 \mathrm{H}, \mathrm{OCH}_{3}\right.$ ), 5.69 (m, $1 \mathrm{H}, \mathrm{CH}$-isoxazoline), 6.69-8.36 (m, 12H, $\mathrm{CH}=\mathrm{N}, 11 \mathrm{Ar}$ $H$ ). Mass (NCI) m/e: $428 \mathrm{M}^{+}$for $\mathrm{C}_{26} \mathrm{H}_{26} \mathrm{~N}_{3} \mathrm{O}_{3} \cdot \mathrm{R}_{\mathrm{f}}=0.48$ (1:1, Hexane:Ethylacetate).

N-(4-(5-(3,4-dimethoxyphenyl)-4,5-dihydroisoxazol-3-yl)phenyl)1-(2,4-dinitrophenyl)methanimine (7)

Yellow powder, yield 70\%, m.p 172-174 ${ }^{\circ} \mathrm{C}$; IR $\left(\mathrm{cm}^{-1}\right)$ : 3047 (aromatic $C-H$ ), 2997(aliphatic $C-H), 1631(C H=N), 1597(C=N), 1512-1340$ Two band N-O. Rf = o.6o (1:1, Hexane: Ethylacetate).

\section{Synthesis of methyl (4-(5-(3,4-dimethoxyphenyl)-4,5-} dihydroisoxazole-3-yl)phenyl)carbamate (8)

This compound was prepared according to the modified procedure described in reported work ${ }^{14}$. A mixture of isoxazoline derivatives 8 (1mmol) and excess of methyl chloroformate $(0.2 \mathrm{ml})$ in acetone (10ml) were strrired for $2 \mathrm{hrs}$. The precipitate formed was filtered, washed with acetone and recrystilized from ethanol

Yellow powder, yield 50\%, m.p 119-120 ${ }^{\circ} \mathrm{C}$; IR $\left(\mathrm{cm}^{-1}\right): 3329$ broad peak $(\mathrm{NH})$, 3003 (aromatic $C-H)$, 2937 (aliphatic $C-H), 1718(C=O), 1604(C=N), 1516(C=C)$. ${ }^{1} \mathrm{HNMR}$ (30o $\mathrm{MHz}, \mathrm{CDCl}$ ) $\delta$ (ppm): 3.37-3.44 (m, $1 \mathrm{H}, \mathrm{CH}$-isoxazoline), 3.68 (s, $\left.3 \mathrm{H}, \mathrm{CH}_{3}\right), 3.75\left(\mathrm{~s}, 3 \mathrm{H}, \mathrm{OCH}_{3}\right), 3.83\left(\mathrm{~s}, 3 \mathrm{H}, \mathrm{OCH}_{3}\right), 3.85-3.87(\mathrm{~m}, 1 \mathrm{H}, \mathrm{CH}$-isoxazoline), $5.64(\mathrm{~m}, 1 \mathrm{H}, \mathrm{CH}$-isoxazoline), 6.94-7.84 (m, 7H, $A r-H), 9.96(\mathrm{~s}, 1 \mathrm{H}, \mathrm{NH})$.
Mass (NCI) m/e: $356 \mathrm{M}^{+}$For $C_{19} H_{20} N_{2} O_{5}, R_{f}=0.56$ (7:3, Hexane: Ethyl acetate).

Synthesis 3-(N-substituted-4-aminophenyl)-5substitutedarylisoxazoline derivatives ${ }^{9,10}$

These compounds were synthesized according to the modified procedure described in the published work ${ }^{15}$. Anhydrous sodium acetate $(1.2 \mathrm{mmol})$ was added to a mixture of isoxazoline derivative $2(1 \mathrm{mmol})$ and the corresponding anhydrides (1mmol) (phthalic or maleic anhydride) in glacial acetic acid ( $3 \mathrm{ml}$ ) then the mixture was refluxed for $1 \mathrm{~h}$. After completion of the reaction (monitored by TLC), the reaction crude was added to crushed ice and stirred. The separated product was filtered and washed with water, dried and recrystallized from ethanol.

\section{2-(4-(5-(3,4-dimethoxyphenyl)-4,5-dihydroisoxazol-3-yl)phenyl)} isoindoline-1,3-dione (9)

Gray powder, yield $68 \%$, m.p 220-222 ${ }^{\circ} \mathrm{C}$; IR $\left(\mathrm{cm}^{-1}\right): 3009$ (aromatic $C-H$ ), 2939 (aliphatic $C-H)$, 1741, $1712(C=O), 1604(C=N), 1518(C=C)$. Mass $(\mathrm{NCI}) \mathrm{m} / \mathrm{e}: 428$ $\mathrm{M}^{+}$For $\mathrm{C}_{25} \mathrm{H}_{20} \mathrm{~N}_{2} \mathrm{O}_{5} . R_{f}=0.48$ (3:7, Hexane:Ethylacetate).

\section{1-(4-(5-(3,4-dimethoxyphenyl)-4,5-dihydroisoxazol-3-yl)phenyl)-}

\section{H-pyrrole-2,5-dione (10)}

Brown powder, yield 76 \%, m.p 139-141 ${ }^{\circ} \mathrm{C}$; IR $\left(\mathrm{cm}^{-1}\right): 3005$ (aromatic $C-H$ ), 2949 (aliphatic $C-H), 1716,1668(C=O), 1606(C=\mathrm{N}), 1518(C=C)$. Mass $(\mathrm{NCI}) \mathrm{m} / \mathrm{e}: 378$ $\mathrm{M}^{+}$For $\mathrm{C}_{21} \mathrm{H}_{18} \mathrm{~N}_{2} \mathrm{O}_{5}, R_{f}=0.13$ (3:7, Hexane:Ethylacetate).

\section{Antimicrobial Studies}

The synthesized isoxazoline derivatives (3-10) were screened for their antimicrobial activity against Escherichia coli, Pseudomonas aeruginosa (Gram negative), Staphylococcus aureus, Streptococcus Spp (Gram positive) as well as Candida albicans by using the well diffusion method (Table 1$)^{16}$. DMSO was used as a control and the test was performed at $2 \mathrm{mg} / \mathrm{mL}$ concentration by using DMSO solvent. Amoxicillin was used as standard drugs. An experiment for each compound was made in triplicate and the average reading was recorded.

\section{Antioxidant study (DPPH. radical scavenging assay)}

TLC autographic assay: Few milligrams of isoxazoline derivatives (3-10) dissolved in methanol were added to the $T L C$ plate by extremely small capillary. After drying, TLC plates were sprayed with methanolic solution of $0.2 \% \mathrm{DPPH}$. The plates were examined half hour after spraying. Potent derivative appears as yellow or blue spots against a purple background ${ }^{17}$.

Spectrophotometric (DPPH) assay: At first 1.0 mL of the samples at concen- 
tration of 100,300 and $500 \mu \mathrm{g} / \mathrm{mL}$ was mixed with $0.5 \mathrm{~mL}$ of DPPH solution (1.3 $\mathrm{mg}$ DPPH / $\mathrm{mL}$ methanol) and the volume was complete to $3 \mathrm{~mL}$ with methanol. The reaction mixture was left to stand for $30 \mathrm{~min}$ in dark place. The control contained all reagents without the sample while gallic acid was used as standard. The DPPH radical scavenging activity was determined by reading the absorbance at $517 \mathrm{~nm}$ against the blank. The capability to scavenge the DPPH radical was calculated by using the following equation: DPPH scavenging effect $(\%)=\left(\mathrm{A}_{0}-\mathrm{A}_{1} / \mathrm{A}_{0}\right)$ $\mathrm{X} 100$, where $\mathrm{A}_{\mathrm{o}}$ is the absorbance of the control reaction, and $\mathrm{A}_{1}$ is the absorbance in the presence of compounds or standards ${ }^{18}$.

\section{Docking study}

AutoDock 4.2 tool was used to specify the affinity of the potent isoxazoline derivatives $(7,8)$ to the binding site of GlcN-6-P synthase as described by the reported reference ${ }^{19}$. The pdb enzyme file of receptor was downloaded from the RCSB Protein Data Bank (PDB code 1MOQ) and used as a fixed molecule. All the water molecules were eliminated and hydrogens were added to the amino acid residues. ChemDraw ultra 7.0 software was used to construct the chemical structure of examined derivatives as mol format, while the open Babel 2.3.1 software was used to build the pdb file. The docking study was achieved by using grid dimensions 30.5, 17.5 and -2.2, respectively. Docking algorithm using Lamarckian Genetic was employed with 150 population size, 10 runs and 2,500,000 maximum number of energy evaluations, while the maximum number of generations was 27,000.

\section{RESULTS AND DISCUSSION}

\section{Organic Synthesis}

Chalcone derivative 1 and the isoxazoline compound 2 were prepared and characterized as described by our previous work ${ }^{20}$. Shiff bases (3-7) were synthesized from the reaction of isoxazoline derivative 2 with different aromatic aldehydes in acidic methanolic solution (Scheme 1).

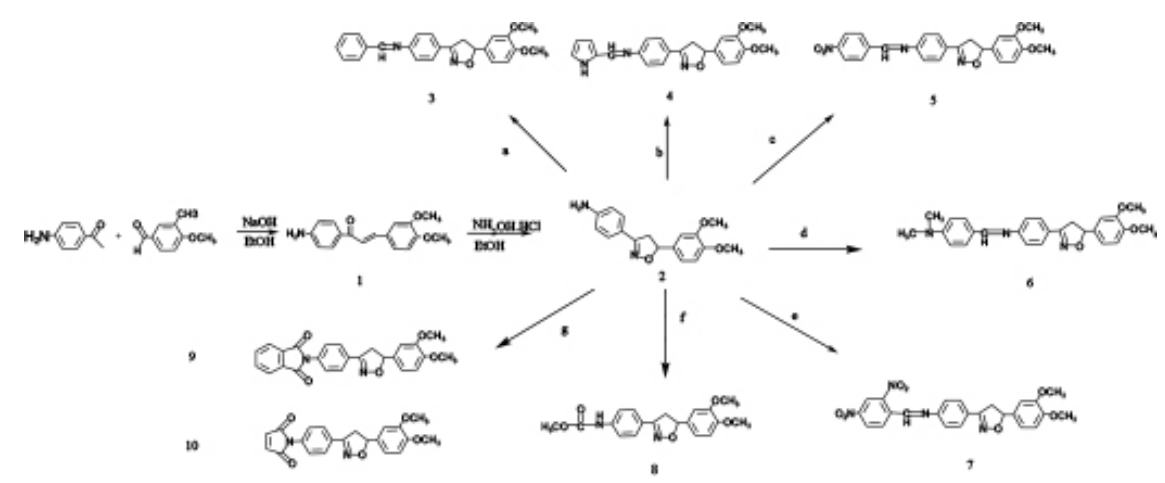

Scheme 1. (a) benzyaldehyde-dimethylacetal, $\mathrm{MeOH}$ (b) pyrrole-2-carboxaldehyde, EtOH (c) p-nitrobenzyaldehyde, EtOH (d) 4-N,N-dimethylbenzylaldehyde, $\mathrm{EtOH}$ (e) 2,4-dinitrobenzylaldehyde, $\mathrm{MeOH}$ (f) methyl chloroformate, acetone(g) phthalic anhydride or maleic anhydride, glacial acetic acid

The structures of the obtained compounds were confirmed by spectral analysis (see experimental section). The FT-IR spectra of compounds (3-7) showed the absorption bands at $1670-1618 \mathrm{~cm}^{-1}, 1606-1593 \mathrm{~cm}^{-1}$ regions due to the stretching vibrations of the $C H=\mathrm{N}$ and $C=N$ groups. The disappearance of the $\mathrm{NH}_{2}$ stretching frequencies strongly enhances the elucidation of prepared compounds. The mass spectra are consistent with the molecular ion peak values of the prepared compounds. The ${ }^{1} \mathrm{HNMR}$ spectra of compound 4 and 5 showed singlet within the $8.89,8.91 \mathrm{ppm}$ regions due to $\mathrm{CH}=\mathrm{N}$ protons with the absent of the singlet signal at 3.88 related to $\mathrm{NH}_{2}$ group in compound 2. The amide derivative 8 was obtained by the reaction of isoxazoline compound (2) with methyl chloroformate in glacial acetic acid. $I R$ spectrum showed broad peak at $3329 \mathrm{~cm}^{-1}$ of $\mathrm{NH}$ stretching and characteristic peak at $1718 \mathrm{~cm}-1$ due to $\mathrm{C}=\mathrm{O}$ group. ${ }^{1} \mathrm{HNMR}$ spectra showed two singlet signals at 3.68 and $9.96 \mathrm{ppm}$ related to $\mathrm{CH}_{3} \mathrm{OCO}$ and $\mathrm{NH}$ protons. The reaction between the isoxazoline derivative 2 with phthalic and maleic anhydride was carried out (Scheme1) and purified by recrystallization from ethanol to yield $\mathrm{N}$-substitutedphthalimide 9 and $\mathrm{N}$-substitutedmaleimide 10 in high yiled. The structures of the N-substituteimide derivatives were confirmed by using IR spectroscopy. The stretching of two carbonyl groups appeared at 1741, 1712 and 1716, $1668 \mathrm{~cm}^{-1}$ for compound 9 and 10, respectively. Further elucidation of molecular ion was confirmed via Mass spectroscopy.

\section{Antimicrobial Activity}

The in vitro assay of the isoxazoline derivatives (3-10) against several microbial species was achieved by using $2 \mathrm{mg} / \mathrm{mL}$ concentration as illustrated in Table 1. The tested compounds displayed auspicious activity against different species. Compound 7 and 8 were the potent agents against gram positive, gram negative as well as Candida Albicans. 
Table 1. In vitro antimicrobial inhibition zone $(\mathrm{mm})$ of the synthesized compounds

\begin{tabular}{|c|c|c|c|c|c|}
\hline \multirow{2}{*}{$\begin{array}{c}\text { Isoxazoline } \\
\text { derivatives }\end{array}$} & \multicolumn{2}{|c|}{ Gram positive } & \multicolumn{2}{c|}{ Gram negative } & Fungi \\
\cline { 2 - 6 } & E.coli & P.aeruginosa & S. aureus & $\begin{array}{c}\text { Streptococcus } \\
\text { Spp }\end{array}$ & C. albicans \\
\hline 3 & 15 & 10 & - & 11 & 9 \\
\hline 4 & - & 11 & 14 & 11 & 15 \\
\hline 5 & 10 & 10 & - & 12 & 14 \\
\hline 6 & 13 & - & - & 10 & 14 \\
\hline 7 & 11 & 14 & 18 & 13 & - \\
\hline 8 & 10 & 14 & 15 & 12 & 14 \\
\hline 9 & 11 & 12 & - & - & 13 \\
\hline 10 & 11 & - & 13 & - & 16 \\
\hline Amoxicillin & 20 & 15 & 33 & 21 & 28 \\
\hline
\end{tabular}

(-) exhibit no activity at specific concentration

\section{Antioxidant Activity}

The scavenging properties of all the synthesized derivatives (3-10) were evaluated against DPPH radical by using TLC autographic assay. The isoxazoline derivatives dissolved in methanol were transferred to the one end of a TLC plate by using spotting capillary. After drying and spraying the DPPH solution, the active compounds $(4-6,8)$ appeared as yellow or blue spots with purple background. The scavenging activity of the lead derivatives $(4-6,8)$ was determined by using spectroscopic method as described in the indicated reference ${ }^{18}$. The relationships between the in vitro percentage inhibition and the concentration of the potent hits $(100,200$ and $300 \mu \mathrm{g} / \mathrm{mL})$ are summarized in Figure 1.
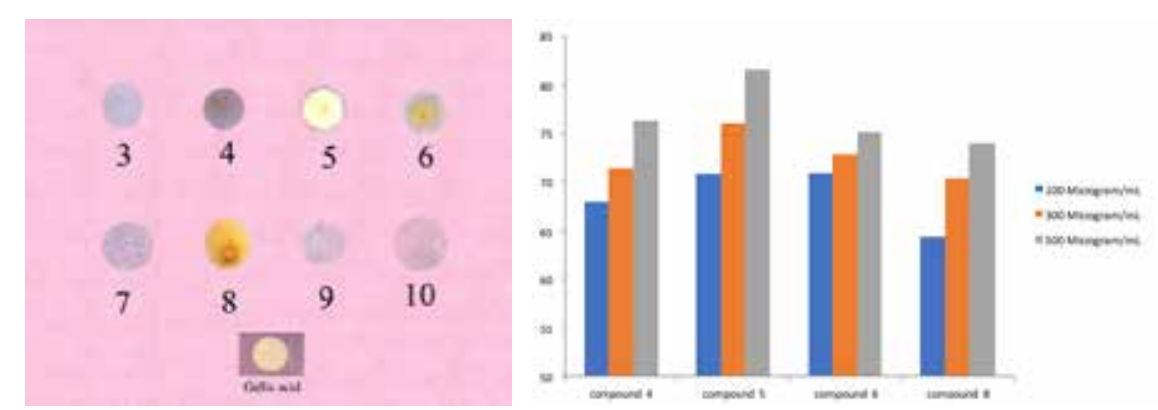

Figure 1. a- TLC autographic assay of the isoxazoline derivatives (3-10), b- Comparison of DPPH scavenging assay of potent compounds $(4-6,8)$

\section{Docking Study}

The docking study of the potent active isoxazoline derivatives $(7,8)$ toward antimicrobial species inside the active pocket of L-Glutamine: D-fructose-6-phosphate amidotransferase, the active target for antimicrobial agents was explored. As described by the X-ray study, the binding pocket of target enzyme including the following subsequent residues, cysteine 300, glycine 301, threonine 302, serine 303 , serine 347 , glutamine 348 , serine 349 , threonine 352 , valine 399 , serine 401 , alanine 602 and lysine 603 as shown in Figure $2^{21}$.

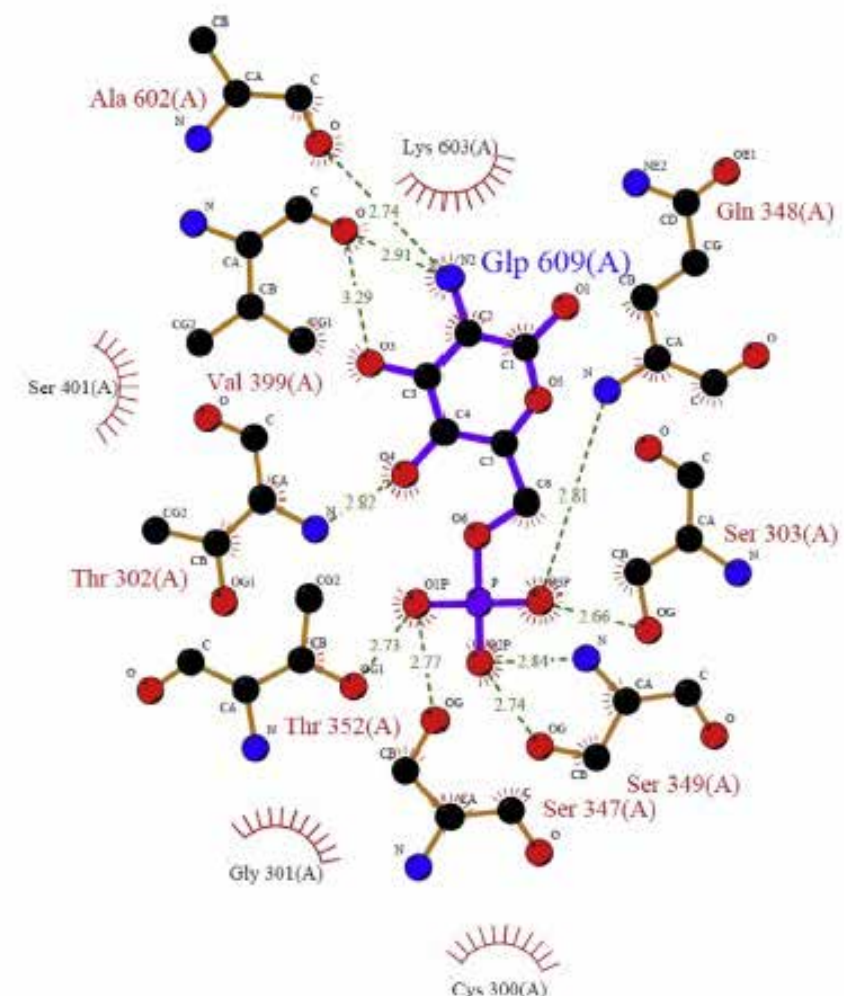

Figure 2. The binding of glucosamine-6-phosphate inside the active site of target enzyme

The binding energy of active compounds inside the known three-dimensional structure of the specific enzyme was explored by using Autodock 4.2. The binding of the best building conformers for compounds 7 and 8 inside the binding pocket of L-Glutamine: D-fructose-6-phosphate amidotransferase is illustrated in Figure 3 . 


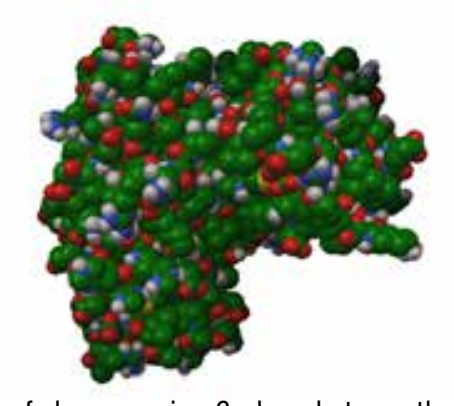

3D structure of glucoseamine-6-phosphate synthase (GIcN-6-p)

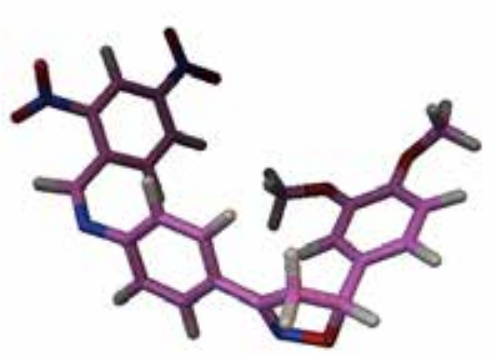

Compound 7

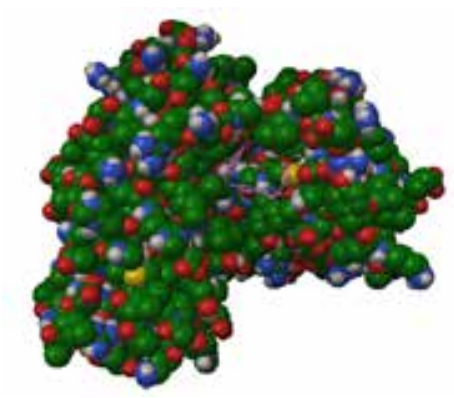

The best conformer of compoud 7 inside binding pocket of GlcN-6-P

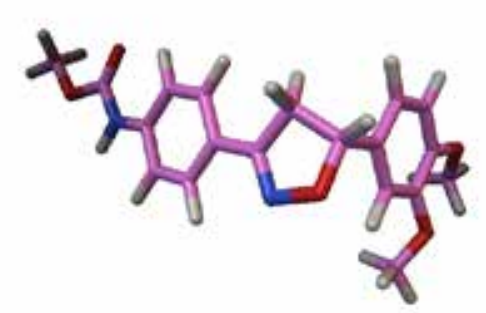

Compound 8

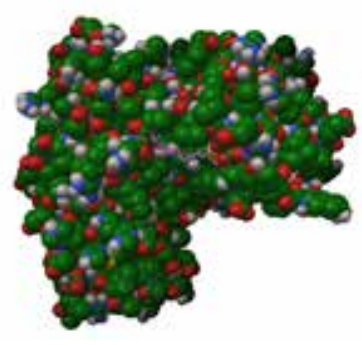
binding pocket of GIcN-6-P
The best conformer of compoud 8 inside

Figure 3. The docking of the best generated conformers of the potent discovered hits (7 and 8) inside the binding pocket of L-Glutamine: D-fructose-6-phosphate amidotransferase (GIcN6-P).

As indicated by molecular docking parameters (Table 1), the high-ranking binding energies of the generated conformer was - 5.31and - $5.68 \mathrm{kcal} \mathrm{mol}^{-1}$ for compound 7 and 8 , respectively. The docking results of all generated conformers of compounds within the binding pocket are strongly enhancing antibacterial and antifungal activities as depicted in Table 1. Furthermore, the inhibition constant
Ki, intermolecular energy and hydrogen bonds were also determined and recorded in Table 2.

Table 2. Docking parameters of isoxazoline compounds (7 and 8)

\begin{tabular}{|c|c|c|c|c|c|c|}
\hline \multicolumn{2}{|c|}{ Compounds } & Binding Energy & $\begin{array}{c}\text { Inhibition } \\
\text { constant (UM) }\end{array}$ & $\begin{array}{l}\text { Intermolecular } \\
\text { entrov }\end{array}$ & H-bonds & Bonding \\
\hline & & -5.31 & 128.24 & -7.7 & 1 & GLN348: HE22: LIG:0 \\
\hline & 2 & -5.24 & 144.17 & -7.63 & 1 & SER604:HN: LIG:0 \\
\hline & 3 & -5.00 & 214.77 & -7.39 & 1 & GLY301:HN: LIG:N \\
\hline & 4 & -4.85 & 280.90 & -7.23 & 2 & GLY301:HN: LIG:N \\
\hline & 5 & -4.77 & 317.38 & -7.16 & 2 & ALA602:HN: LIG: 0 \\
\hline & 6 & -4.58 & 440.84 & -6.96 & - & GLY301:HN: LIG:N \\
\hline & 7 & -4.39 & 602.48 & -6.87 & 3 & ALA602:HN: LIG: 0 \\
\hline & 8 & -4.28 & 723.19 & -6.67 & 1 & - \\
\hline & 9 & -3.87 & 1460.00 & -6.26 & 1 & GLN348: HE22: LIG:0 \\
\hline & 10 & -3.55 & 2490.00 & -5.94 & - & LIG:0: SER604:0 \\
\hline 8 & 1 & -5.68 & 68.83 & -7.47 & 1 & LYS603:HN: LIG:N \\
\hline & 2 & -5.68 & 68.30 & -7.47 & 2 & GLY301:HN: LIG: 0 \\
\hline & 3 & -5.63 & 75.14 & -7.42 & 1 & GLY301:HN: LIG: 0 \\
\hline & 4 & -5.53 & 88.24 & -7.23 & 1 & - \\
\hline & 5 & -5.19 & 157.24 & -6.98 & - & ASP354:HN: LIG:0 \\
\hline & 6 & -5.13 & 173.35 & -6.92 & - & LIG:H: ASN305:0D1 \\
\hline & 7 & -5.11 & 180.95 & -6.90 & - & ASN305:HD22 LIG:0 \\
\hline & 8 & -5.09 & 187.11 & -6.88 & 1 & ASN305:HD22: LIG: 0 \\
\hline & 9 & -4.95 & 233.34 & -6.74 & 1 & GLY301:HN: LIG: N \\
\hline & 10 & -4.67 & 380.49 & -6.46 & 1 & - \\
\hline & & & & & & - \\
\hline & & & & & & - \\
\hline & & & & & & ASN600:HD22: LIG: 0 \\
\hline & & & & & & ASN600:HD22: LIG: 0 \\
\hline & & & & & & ASN600:HD22: LIG: 0 \\
\hline
\end{tabular}

\section{CONCLUSION}

The present work summarized the synthesis of novel isoxazoline derivatives as promising antimicrobial agents. The scavenging activity of the potent antioxidant derivatives was estimated by using DPPH radical. On the other hand, docking study using Autodock 4.2 was achieved to illustrate the bound state of ligand enzyme complex for the potent discovered hits. 


\section{ACKNOWLEDGMENT}

The authors would like to thank, Mustansiriyah University (www.uomustansiriyah.edu.iq) Baghdad, Iraq for its support in the present work.

\section{REFERENCES}

1. World Health Organization. The evolving threat of antimicrobial resistance: Options for action, 2012.

2. Swedish Council on Health Technology Assessment in Health Care (SBU). Preventing disease with antioxidants, 1997. SBU report no 135/1-135/3 (Stockholm, in Swedish).

3. Jadhav, S.B.; Shastri, R.A.; Gaikwad, K.V.; Gaikwad S.V. Synthesis and Antimicrobial Studies of Some Novel Pyrazoline and Isoxazoline Derivatives. E-Journal of Chemistry. 2009, 6(S1) S183-S188.

4. Filali, I.; Bouajila, J.; Znati, M.; Bousejra-El Garah, F.; Jannet H.B. Synthesis of new isoxazoline derivatives from harmine and evaluation of their anti-Alzheimer, anti-cancer and antiinflammatory activities. $J$ Enzyme Inhib Med Chem. 2014, 1475-6366 (print), 1475-6374.

5. Al Houari, G.; Kerbal, A.; Bennani, B.; Baba, M.F.; Daoudi, M.; Hadda, T.B. Drug design of new antitubercular agents: 1,3-dipolar cycloaddition reaction of para-substituted-benzadoximes and 3-para-methoxybenzyliden-isochroman-4-ones. General Papers, 20o8, 1551-7012, 42-50.

6. Pravin O. P.; Sanjay B. B. Synthesis and Antidepressant Activity of Some New 5-(1H-Indol3-yl)-3-(substituted aryl)-4,5-dihydroisoxazoline Derivatives. Journal of Chemistry, 2013. Article ID 637205, 7 pages.

7. Zeng, Y.; Zhang, H.; Wang, B.; Zhang, L.; Xue, A.; Zhao, X.. Synthesis and biological evaluation of various new bis-isoxazoline derivatives as potential antioxidant additives. Journal of Chemical Research. 2016, 40, 558-563.

8. Castellano S.; Kuck D.; Viviano, M.; Yoo, Jakyung.; Lopez-Vallejo, F.; Conti, P.' Pinto, L. T.; Medina-Franco, A.J.L.; Sbardella, G. Synthesis and Biochemical Evaluation of $\Delta 2$-Isoxazoline Derivatives as DNA Methyltransferase 1 Inhibitors. J. Med. Chem. 2011, 54, 7663-7677.

9. Bearne, S.L.; Blouin, C. Inhibition of Escherichia coli glucosamine-6-phosphate synthase by reactive intermediate analogues. J. Biol. Chem. 20oo, 275(1), 135-140.

10. Morris, G.M.; Goodsell, D.S.; Halliday, R.S.; Huey, R.; Hart, W.E.; Belew, K.R.; Olson, A.J. Automated docking using a Lamarckian genetic algorithm and an empirical binding free energy function. J. Comput. Chem. 1998, 19 (1), 639-1662.

11. Mohammed, O.J.; Radi, M.F.; Abdula, A.M.; AL-ahdami, B.W.; Rodhan, W.F.; Sha'aban, H.G. Synthesis of four chalcone derivatives bearing heterocyclic moieties as new Ache inhibitors by docking simulation. Int. J. Chem. Sci. 2015, 13(1), 157-166.

12. Abdel-Rahman, A.A.H.; Abdel-Megied, A.E.S.; Hawata, M.A. M.; Kasem, E.R.; Shabaan, M.T. Synthesis and Antimicrobial Evaluation of Some Chalcones and Their Derived Pyrazoles, Pyrazolines, Isoxazolines, and 5,6-Dihydropyrimidine-2-(1H)-thiones. Chemical monthly, 2007. 138, 889-897.

13. Seelam, N.; Shrivastava, S.P. Synthesis and in vitro study of [1,3,4]thiadiazol-2yl- 3,3a,5,6tetrahydro-2H-pyrazolo[3,4-d]thiazoles as antimicrobial agents. J. Saudi. Chem. Soc. 2012, 20, 33-39.

14. Velikorodov, A.V.; Imasheva, N.M. Synthesis of Carbamate Derivatives of 2,3-Dihydro-4H-1,4-benzoxazine. Russ J Org Chem. 2oo8, 44(3), pp. 369-372.
15. Kavitha, K.; Vangala R.R.; Khagga M.; Sarbani P. Lewis acid free high-speed synthesis of Nimedesulide-based novel N-substituted cyclic imides. J. Braz. Chem. Soc. 2010, 21, 1060-1064. 16. Kavitha K., Vangala R. Reddy, Khagga M., Sarbani P. Lewis acid free high-speed synthesis of Nimedesulide-based novel N-substituted cyclic imides. J. Braz. Chem. Soc. 2010, 21, 10601064 .

17. Cuendet, M.; Hostettmann, K.; Potterat, O.; Dyatmiko, W. Iridoid Glucosides with Free Radical Scavenging Properties from Fagvaea blumei. Helv. Chim. Acta. 1997, 80(4), 1144-1152.

18. Sapnakumari, M.; Narayana, B.; Sarojini, B.K.; Madhu, L.N. Synthesis of new indazole derivatives as potential antioxidant agents. Med Chem Res. 2014, 23, 2368-2376.

19. Shia J.S.; Al-bayati, R.I.H.; Abdula. A.M.; Saorb, K.Y. docking study of some n-[4-(4arylidene)-2-(4-substituted-phenyl)-5-oxo-4.5-dihydro-imidazol-1-yl]-benzenesulfonamide derivatives against glucosamine-6-phosphate synthase. Int. J. Chem. Sci. 2015, 13(4), 1982-1990 20. Ismail A. H.; Abdula, A. M.; Hama, Y. N. Synthesis, characterization and biological evaluation of new heterocyclic compounds from chalcone derivatives. 2017, Thesis, department of Chemistry, College of Science, Al-Mustansiriyah University.

21. Teplyakov, A.; Obmolova, G.; Badet-Denisot, M-A.; Badet, B.; Polikarpov, I. Involvement of the $\mathrm{C}$ terminus in intramolecular nitrogen channeling in glucosamine 6-phosphate synthase: evidence from a $16 \mathrm{~A}^{\circ}$ crystal structure of the isomerase domain. Structure $\mathbf{1 9 9 8}, 6(8), 1047^{-}$ 1055. 